\title{
FOSTER, BENJAMIN R. THE AGE OF AGADE. INVENTING EMPIRE IN ANCIENT MESOPOTAMIA. NEW YORK: ROUTLEDGE, 2016. 438 p. ISBN: 978-1-138-90971-7
}

Alexandre Galvão Carvalho ${ }^{1}$

\section{Palavras-chave}

Mesopotâmia; Acádia; Benjamin Foster.

O renomado assiriólogo Benjamin Foster apresenta, nesta ambiciosa obra, um painel amplo, detalhista e instigante do primeiro império do mundo, o Império Acadiano (2334-2193 a.e.c.). Investigando e se perguntando sobre a história política e social; a cultura material, vida cotidiana, espiritualidade, artes e letras; o legado da era de Acádia e os motivos da sobrevivência em épocas posteriores desse período, Foster se propõe a mergulhar, em sua interpretação, nas variadas fontes textuais e arqueológicas, explorando análise de superfícies, plantas baixas, enterros, cerâmica, crônicas e coleções de utensílios. Apesar de afirmar que seu trabalho é de cunho documental e descritivo, em vez de explicações de causas e efeitos, o autor se posiciona em relação a debates no seio da historiografia acerca do período, mesmo procurando sempre apresentar todas as visões acerca dos temas abordados. O fascínio que o Império Acadiano exercia sobre a sociedade mesopotâmia posterior e mesmo sobre outras sociedades do Antigo Oriente Próximo é interrogado neste livro pela diferenciação entre a dinastia acadiana e suas realizações. Traçar este percurso não é fácil, pois o autor deixa claro que as evidências, apesar de ricas, são fragmentadas, reescritas e mesmo esmagadas pelas gerações posteriores.

Foster define a Era Acadiana, no seio da longa história da Mesopotâmia, por meio de uma aceleração cultural e política inicial, com um clímax no meio e uma desintegração abrupta de sua ordem política, separando de forma incisiva o que havia antes e o que veio depois. Logo no primeiro capítulo, Foster descreve a Ascensão e queda do Império Acádio por meio da biografia dos grandes reis da dinastia acadiana, destacando suas realizações e seus legados. Contudo, o autor fica nos devendo uma explicação mais geral acerca desse aparecimento e sua abrupta queda, como por exemplo: diferenciação entre sul e norte em relação à

\footnotetext{
1 Professor Pleno - Universidade Estadual do Sudoeste da Bahia, Vitória da Conquista, Brasil. E-mail: galvaocarvalho@uol.com.br.
} 
organização política da Mesopotâmia; os elementos culturais sumerianos, que já se constituíam em um poderoso elemento agregador pré-acadiano e as deficiências das esferas de interação do estado acadiano, motivo de várias rebeliões, elemento poderoso de sua queda. Essas questões poderiam enriquecer a análise de Foster, mesmo que ele não se propusesse a isso.

No segundo capítulo, Benjamin Foster apresenta um quadro amplo da sociedade acadiana, ressaltando o desenvolvimento de uma elite, administrativa e militar, que assegurou os principais recursos materiais do império, em particular, por meio da posse de terras em uma sociedade em que a propriedade privada estava substituindo a propriedade comunal. Assim, vendas, empréstimos e transferências de bens móveis foram escritos e testemunhados, retratando significativas alterações no status social. Foster aborda o sistema de clientela e patronato no império acadiano com o objetivo de demonstrar o quanto este sistema foi útil na gestão do império. Os recursos do império foram distribuídos por meio de laços de dependência que resultaram em uma teia de fidelidades e deveres na qual o poder central conseguia oferecer novas oportunidades aos súditos. Assim, esse sistema criou novos grupos sociais e reorganizou a antiga sociedade suméria, com impactos inclusive sobre a relação entre o poder real e o templo. Foster encerra o capítulo com as rebeliões e resistências à hegemonia acadiana, amplamente registradas em inscrições comemorativas, que são, segundo o autor, oportunidades para provar a supremacia e o triunfo dos reis acadianos, porém indicam as dificuldades do império de expropriar as melhores terras das elites sumerianas, de destruir as lideranças locais e de dominar completamente os sacerdotes dos templos, que, apesar dos interesses mútuos, perdem influência política e econômica com a chegada dos acadianos.

O sítio arqueológico da cidade de Acádia nunca foi encontrado. Apesar dessa lacuna arqueológica, não há dúvida no seio da historiografia acerca da existência e do papel do império acadiano, que, segundo Foster foi uma entidade mantida pela força, com medidas administrativas, propagandistas e culturais, iniciadas por Sargão, com o objetivo de homogeneizar a enorme heterogeneidade do universo sumério e conquistar territórios de diferentes regiões. A essência do novo estado foi a institucionalização dos conflitos armados, além de alianças em regiões periféricas, mantidas por casamentos e um comércio de longa distância, fundamental para o suprimento de matérias-primas e garantia de recursos materiais para o centro do império. A prática de destruição sistemática das muralhas das cidades-estados, uma forma de destruição de um símbolo de identidade social e político, paradoxalmente objetivava quebrar resistências, mas também alcançar a integração imperial. A escrita, com o 
desenvolvimento da caligrafia imperial, foi redirecionada para inscrições propagandistas, com ênfase na guerra. Estátuas impressionantes foram esculpidas para dar maior impacto às mensagens reais, produtos de uma brilhante iniciativa artística. Dessa forma, em todo o reino, os monumentos destacavam a figura do rei e sua corte, proclamando uma nova visão de mundo. Os elementos-chave do programa acadiano enfatizavam uma nova cidade, Acádia, que é o primeiro exemplo de uma nova capital, criada por um ato político, além de Nippur como centro da liga das cidades sumerianas.

Apesar de Foster priorizar uma análise descritiva, ele não fica imune ao debate da economia antiga. Nos capítulos em que investiga a produção agrícola, o comércio, as oficinas manufatureiras, os trabalhadores, as trocas, os mercados, o transporte e os produtos importados, ele caracteriza o império acadiano como de natureza tributária em oposição ao modelo redistributivo, defendido por assiriólogos substantivistas, como é o caso de Johannes Renger. Foster acredita que o modelo redistributivo está mais próximo do período anterior, sumério, marcado pela redistribuição do excedente pelo setor público para a população e ausência de mercados. Seus argumentos se aproximam da perspectiva formalista para caracterizar a economia acadiana do terceiro milênio. A prata, usada como dinheiro "moderno"; a presença de mercados para realização de transações comerciais e o papel do comerciante, elemento mediador junto àqueles que queriam adquirir prata e bens de prestígio são condições sine qua non para o desenvolvimento de novos horizontes culturais, político e comercial, que agudizaram e possibilitaram a ampliação dos interesses privados. Tudo isso foi viabilizado por uma política estatal agrícola bem definida, no qual o excedente agrícola da Suméria foi mais do que suficiente para sustentar a política de redistribuição do Estado, principalmente ao exército, e não mais só baseada na redistribuição de ração para toda a população, que encontrou outros meios de subsistência. Entretanto, a utilização de mão de obra livre para a construção de obras públicas ainda é uma prática que permanece do período anterior

A gestão e manutenção do império acadiano não poderiam ser sustentadas apenas por ações econômicas e sociais. Foster se debruça sobre os aspectos ideológicos de sustentação e legitimação do poder acadiano, apontando o nascimento de uma tradição religiosa em relação ao período anterior. Apesar do Dinástico não ser caracterizado pela unificação política das cidades-estados mesopotâmias, o aspecto religioso contribui para a construção de uma identidade comum entre os cidadãos da região mesopotâmia. Assim, a realeza acadiana procurará consolidar o panteão mesopotâmio em seu proveito. Foster destaca o papel dessa construção 
como um meio da realeza afirmar a unidade política, sendo a inclusão do rei acadiano no seio do panteão, como um deus, uma novidade na religiosidade mesopotâmia. Os reis acadianos procuraram integrar as tradições religiosas sumerianas às tradições religiosas do norte mesopotâmio, por meio de um sincretismo que objetivava reafirmar $o$ domínio político junto ao sistema cultural das sociedades conquistas. Foster destaca o papel de Enheduanna, filha de Sargão, sacerdotisa do templo do deus lua em Ur e autora de diversos hinos em sumério, que versam sobre o retorno dos diversos deuses das cidades-estados sumerianas aos seus respectivos santuários, após as vitoriosas campanhas de Sargão. Entretanto, Foster não sublinha o caráter subversivo das ações de Sargão, que levou o rei de Uruk, Lugalzagesi, acorrentado até as portas do templo de Enlil, exaltando sua conquista e seu papel de salvador, em vista do abandono dos deuses ao rei e à elite citadina. Sargão reordena e manipula a ideologia sumeriana em seu proveito, na medida em que mostra a necessidade de intervenção e de restauração de uma nova ordem, produto de uma vontade divina.

A tradição, criada pelos reis acadianos de que não tinham rivais, propagandeada em monumentos e textos escritos, perdurou por muito tempo na cultura mesopotâmia. O império acadiano foi lembrado por muito tempo e se tornou modelo de realeza para futuros reis, que enalteciam o império acadiano como um novo começo e admiravam o sucesso material e guerreiro, expressado nas diversas lendas, épicos, presságios e crônicas, copiadas e retransmitidas por mais de 1200 anos. Mario Liverani (1993), no seio do debate sobre o cerne histórico dos documentos acerca do período acadiano, prefere levantar a hipótese de que os textos que tratam dos reis acadianos sugerem problemas políticos que estavam em debate na época em que foram escritos. O conjunto de materiais celebrativos e anti-celebrativos, produzidos pelos escribas da Babilônia antiga, com um repertório fraseológico, além de narrativas genéricas de vitórias e conquistas, refletem os debates políticos da Babilônia antiga e tardia sobre as diferentes opiniões acerca de tomada de decisões, travadas nos círculos próximos da realeza. Foster contribui com essa tese de Liverani ao localizar as origens dos presságios, de algumas crônicas e lendas acerca dos reis acadianos. No caso de Sargão, Foster nos mostra que os presságios e as inscrições reais não são contemporâneas de sua época e remetem a contextos históricos posteriores à vida do monarca. A comparação dos presságios escritos e inscrições reais inclusive apresenta algumas incongruências acerca do rei e de seus filhos. Epítetos atribuídos a Sargão, rei sem rival, por exemplo, parecem ser característicos de períodos posteriores. Campanhas de Sargão indicam terem sido levadas a cabo por Rimush, mas foram associadas a Sargão por conveniência. Além 
disso, A crônica dos primeiros reis ressalta o papel da cidade da Babilônia diante das conquistas de Sargão e a importância de Marduk, que teria punido Sargão por ter criado uma réplica da Babilônia, Acádia. Na verdade, a crônica valoriza a cidade da Babilônia, cidade mais importante da Mesopotâmia, na época em que a crônica foi escrita.

Finalmente, Foster encerra o livro com uma oportuna e excelente análise sobre a historiografia moderna do período acadiano. Divide a produção historiográfica em cinco fases, de 1861 aos dias atuais, caracterizando cada período a partir das descobertas de fontes, ênfases interpretativas e tendências historiográficas. A primeira fase (1814-1914) é dominada por uma agenda ampla sobre a natureza da realeza com a descoberta de uma extensa documentação predominante textual e em menor número arqueológico, já marcada por uma grande quantidade de documentos de períodos posteriores ao acadiano, despertando dúvidas acerca da credibilidade desses documentos. O segundo momento, de 1914 a 1947, é marcado pela ampliação das evidencias textuais, que permitiram comparar e contrastar presságios com a descoberta de novas obras literárias. A terceira fase, 1947 a 1971, é marcada por importantes sínteses históricas do período acadiano. Foster resgata trabalhos de autores e escolas pouco conhecidos, como no caso Tyumenev e Diaknov, da escola russa, elucidando as preciosas contribuições destes autores, em particular a exploração de uma série de documentos administrativos que iluminam importantes aspectos da sociedade acadiana, poucos explorados até então. Além destes autores, Liverani, Gadd e Botero também aparecem aqui, com inovações importantes em relação ao período anterior. A quarta fase (19711993) caracterizou-se por um interesse crescente na história social e econômica, com substancial aporte arqueológico e com estudos detalhados de documentos administrativos de Nippur, Umma, Adab, bacia de Himrin e outros locais. A quinta fase, de 1993 até os dias atuais, foi dominada por uma enxurrada de novas fontes arqueológicas, provenientes de saques de sítios arqueológicos no Iraque, iniciadas com a Guerra do Golfo (1991). Depois da leitura desse capítulo, fica a sensação de que o mesmo poderia ter aparecido no início da obra, pois indicaria ao leitor como Foster se posiciona em relação a algumas temáticas do debate historiográfico.

O livro de Foster preenche uma lacuna importante no seio da historiografia da Mesopotâmia, pois o conhecimento e o manejo dessa produção historiográfica, com uma bibliografia rica acerca do tema, nos proporcionam uma rica visão acerca de uma sociedade e época que já, no mundo antigo, despertavam fortes interesses dos contemporâneos. É, portanto, uma obra que merece uma urgente tradução para a língua portuguesa. 


\section{Referência Bibliográfica}

FOSTER, B. R. The age of Agade. Inventing empire in Ancient Mesopotamia. New York: Routledge, 2016. 438 p.

LIVERANI, M. (Coord.). The first world empire. Structure, ideology, Tradictions. Padova: Herder editrice e Liberia, 1993, p. 25-40. 